\title{
Armazenamento de umbu-cajá em pó ${ }^{1}$
}

\author{
Storage of umbu-cajá powder \\ Ranilda Neves Gomes da Silva ${ }^{2}$ Rossana Maria Feitosa de Figueirêdo $^{3}$
Alexandre José de Melo Queiroz ${ }^{3}$ Pablícia de Oliveira Galdino ${ }^{2}$
}

\section{RESUMO}

Foi estudada a influência do tipo de embalagem sobre polpa de umbu-cajá em pó armazenada durante 60 dias. As amostras armazenadas em dois tipos de embalagem, laminada e de polietileno, foram avaliadas, a cada 10 dias, por meio dos parâmetros: umidade, ácido ascórbico, $\mathrm{pH}$, acidez total titulável, sólidos solúveis totais, açúcares redutores e cor (luminosidade, intensidade de vermelho e intensidade de amarelo). Constatouse que a embalagem laminada protegeu com maior eficiência as amostras armazenadas, preservando melhor a acidez total titulável, a umidade e os parâmetros de cor luminosidade, intensidade de vermelho e de amarelo. Os teores de açúcares redutores, $\mathrm{pH}$ e ácido ascórbico não foram afetados pelo tipo de embalagem, e o $\mathrm{pH}$ não foi afetado pelo tempo de armazenamento.

Palavras-chave: Spondias spp., embalagem, conservação.

\section{ABSTRACT}

The influence of the packing type on umbu-caja powder stored during 60 days was studied. The samples stored in two packing types, laminated and polyethylene materials, were evaluated each 10 days through the moisture content, ascorbic acid, pH, titratable acidity, soluble solids, reducers sugars and color (brightness, red and yellow intensity) parameters. It was verified that the laminated packing protected with higher efficiency the stored samples, preserving better the titratable acidity, the moisture and the brightness, red and yellow intensity color parameters. The reducers sugars contents, $p H$ and ascorbic acid were not affected by packing type, and the time of storage didn't modify the $\mathrm{pH}$.
Key words: Spondias spp., foam-mat, keeping.

\section{INTRODUÇÃO}

A umbu-cajazeira é uma planta arbórea, da família Anacardiaceae, resultante do cruzamento natural entre a cajazeira (Spondias mombim) e o umbuzeiro (Spondias tuberosa). É uma frutífera tropical nativa do nordeste brasileiro, de fácil propagação, que apresenta grandes perspectivas de inserção no mercado interno de frutas exóticas, especialmente na forma de polpa, sucos e sorvetes (RITZINGER et al., 2001).

Dentre as técnicas empregadas para a manutenção da qualidade pós-colheita de frutas, a desidratação, além de ser utilizada como método de conservação impedindo a deterioração e perdas do valor comercial, resulta ainda em uma transformação do produto, agregando valor e dando origem a uma nova opção no mercado. $\mathrm{O}$ processo de secagem em camada de espuma (foam-mat drying) consiste, basicamente, de três etapas: produção suco ou polpa em forma de uma espuma estável, utilizando-se aditivos; secagem do material em camada fina até desidratação final; desintegração da massa seca em

\footnotetext{
${ }^{1}$ Parte da dissertação de mestrado apresentada pelo primeiro autor, para obtenção do grau de Mestre em Engenharia Agrícola, Universidade Federal de Campina Grande.

${ }^{2}$ Universidade Federal de Campina Grande, Campina Grande, PB, Brasil.

${ }^{3}$ Universidade Federal de Campina Grande, Av. Aprígio Veloso, 882, CP 10.017, 58109-970, Campina Grande, PB, Brasil. E- mail: rossana@deag.ufcg.edu.br. Autor para correspondência.
} 
escamas e, finalmente, em pó (UBOLBI, 1971; TRAVAGLINI et al., 2001). Este processo pode ser executado em temperaturas relativamente baixas, em torno de $70^{\circ} \mathrm{C}$, e mantém alta qualidade e boa estabilidade dos produtos, tendo sido testados em: café, sucos de laranja, grapefruit, uva, carambola, banana, abacaxi, coco, batatas, alimento para crianças, leites, ameixa, maçã, sopas, cremes, ovos, tomate, acerola, tamarindo e outros produtos (UBOLBI, 1971; SOARES et al., 2001; VERNON-CARTER et al., 2001; SANKAT \& CASTAIGNE, 2004).

A qualidade dos produtos desidratados se altera com o tempo de armazenamento, devido a diversas reações de natureza enzimática, oxidativa entre outras. De maneira geral, tais produtos, quando embalados, de forma a serem protegidos para evitar o contato com o oxigênio e o ganho de umidade, apresentam maior vida-de-prateleira. De acordo com ALVES (2001) a vida-de-prateleira depende, fundamentalmente, da proteção oferecida pela embalagem contra a absorção de umidade presente no ambiente de estocagem.

Os plásticos são os materiais de embalagens mais utilizados e englobam, entre outros, filmes, sacos, tubos, engradados e os frascos. Os principais plásticos usados, são: o polipropileno, poliestireno, cloreto de polivinila, polietileno tereftalado, polietileno de alta densidade e o polietileno de baixa densidade. $\mathrm{O}$ polietileno tem baixa permeabilidade à água, excelente características de isolamento elétrico, resistente aos ácidos, álcalis e solventes orgânicos (PIERGIOVANNI, 1998). Os laminados são embalagens compostas em que são sobrepostos filmes plásticos, de alumínio, papel ou papelão e outro filme plástico (BOBBIO \& BOBBIO, 1992). São adequados para produtos sensíveis a reações de oxidação, atuando como barreira ao oxigênio e à luz (GARCIA et al., 1989).

O presente trabalho foi realizado com o objetivo de avaliar a influência do tipo de embalagem sobre o armazenamento a temperatura ambiente de polpa de umbu-cajá em pó, produzida pelo método camada de espuma.

\section{MATERIAL E MÉTODOS}

O trabalho foi desenvolvido no Laboratório de Armazenamento e Processamento de Produtos Agrícolas/UFCG, em Campina Grande, PB. Frutos de umbu-cajá (Spondias spp), provenientes da região de Açu, Rio Grande do Norte, foram processados em despolpadeira mecânica, separando-se a porção comestível dos frutos (polpa integral) das sementes e cascas. A seguir, foi elaborada uma formulação composta da polpa integral de umbu-cajá e aditivos (emulsificante, estabilizante e espessante). A formulação foi espalhada sobre bandejas de aço inoxidável e levada para desidratar em estufa com circulação de ar, sob temperatura de $70^{\circ} \mathrm{C}$. Após seco, o produto foi triturado em liqüidificador doméstico, para obtenção de material finamente pulverizado. As 42 amostras em pó foram então acondicionadas em embalagens laminadas (21 amostras) e de polietileno de baixa densidade (21 amostras), contendo cada uma $25 \mathrm{~g}$ do produto, sendo a seguir armazenadas a temperatura ambiente por 60 dias. Durante o armazenamento, acompanhou-se a evolução das características das amostras por meio de análises periódicas, realizadas a cada dez dias.

A embalagem de polietileno foi elaborada com polietileno de baixa densidade, enquanto a laminada era composta de camadas de polietileno tereftalato, polietileno, alumínio e polietileno.

As análises do umbu-cajá em pó seguiram as seguintes metodologias: umidade, determinada pelo método descrito pelo INSTITUTO ADOLFO LUTZ (1985); ácido ascórbico, método da AOAC (1997) modificado por BENASSI \& ANTUNES (1998); pH, determinado mediante o método potenciométrico; acidez total titulável e açúcares redutores, determinados pelos métodos da AOAC (1997); sólidos solúveis totais ( $\left.{ }^{\circ} \mathrm{Brix}\right)$, por leitura direta na amostra reconstituída em refratômetro do tipo Abbe; medida instrumental da cor, realizada utilizando-se colorímetro Minolta, modelo CR 10, obtendo-se os valores de $L^{*}, a^{*}$ e b*: em que $L^{*}$, é a luminosidade, $a^{*}$ define a transição da cor verde (-a) para a cor vermelha $(+a)$, e b* representa a transição da cor azul (-b) para cor amarela $(+b)$.

A análise estatística dos dados experimentais foi realizada utilizando-se o programa computacional ASSISTAT versão 6.0 (SILVA \& AZEVEDO, 2002), segundo o delineamento inteiramente casualizado com três repetições. A comparação das médias foi feita pelo teste de Tukey a de 5\% de probabilidade de erro. A seguir, os dados de cada embalagem foram submetidos à regressão polinomial na análise da variância (teste F) e apresentadas as equações com o maior coeficiente de determinação $\left(r^{2}\right)$ em que houve efeito significativo do tempo.

\section{RESULTADOS E DISCUSSÃO}

Os pontos experimentais, representando os valores médios da umidade das amostras de umbu-

Ciência Rural, v. 35, n. 5, set-out, 2005. 
cajá em pó em função do tempo de armazenamento, nas embalagens laminadas e de polietileno, com as respectivas curvas de ajuste por equação quadrática (Figura 1a), evidenciam um aumento da umidade das amostras em embalagem de polietileno a partir dos dez dias de armazenamento, atingindo um valor máximo aos 40 dias. A partir de 40 dias, não mais se observam acréscimos. As umidades das amostras armazenadas em embalagem laminada foram mantidas nos níveis iniciais até os 40 dias; a partir de 50 dias,

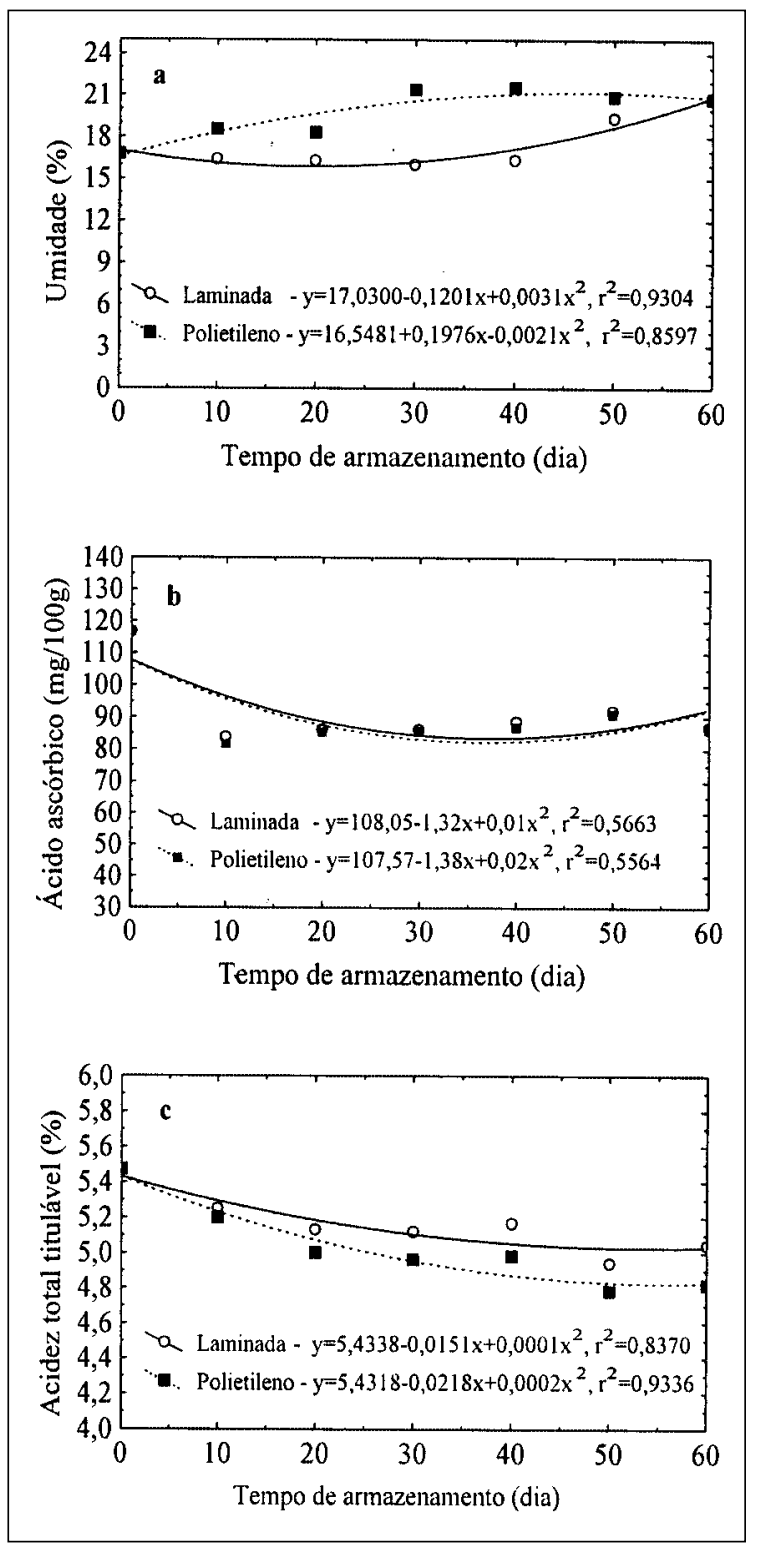

Figura 1 - Valores experimentais da umidade (a), ácido ascórbico (b) e acidez total titulável (c) em função do tempo de armazenamento do umbu-cajá em pó, em diferentes embalagens, com respectivas curvas de ajuste. iniciou-se um aumento que culminou aos 60 dias em um valor semelhante ao medido nos mesmos 60 dias nas amostras armazenadas em polietileno. Comparando o efeito das embalagens, tem-se que a embalagem laminada favoreceu a manutenção dos valores iniciais até os 40 primeiros dias, enquanto a embalagem de polietileno não preservou os teores originais além dos 20 dias. A partir dos 50 dias, não se tem diferença significativa entre as umidades das amostras em embalagem laminada e de polietileno.

Ao final do armazenamento, as amostras em embalagem laminada absorveram 24,5\% de umidade em relação ao teor inicial, enquanto as amostras em embalagem de polietileno absorveram $24,0 \%$. FIGUEIRÊDO et al. (2001), utilizando embalagem laminada com especificação similar à da embalagem utilizada no presente trabalho, não detectaram alterações na umidade durante o armazenamento do suco de acerola microencapsulado, enquanto GOMES (2002), utilizando embalagem de polietileno, verificou aumento de 51,31\% na umidade de polpa de acerola desidratada no final de um armazenamento de 60 dias.

Os dados experimentais para os teores de ácido ascórbico das amostras armazenadas, ajustados por equação do tipo quadrático (Figura 1b), evidenciam em ambas as embalagens reduções acentuadas entre o tempo zero e os 10 dias iniciais do armazenamento, totalizando diminuições de 25,5\% na embalagem laminada e $25,9 \%$ na embalagem de polietileno. A partir de dez dias, os teores se mantiveram praticamente estáveis até o final do armazenamento mantendo médias semelhantes ao longo do tempo nos

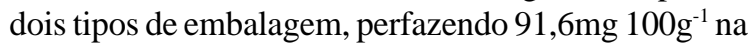
embalagem laminada e $90,6 \mathrm{mg}^{100 \mathrm{~g}^{-1}}$ na embalagem de polietileno. Em todos os tempos, os teores de ácido ascórbico se mantiveram sem diferença significativa entre as duas embalagens, demonstrando que não houve influência do nível de proteção sobre os percentuais desse constituinte. Resultados aproximados foram relatados para polpa de acerola em pó armazenada em embalagem de polietileno, a qual sofreu uma diminuição de $29,72 \%$ no teor de ácido ascórbico ao final de 60 dias (GOMES, 2002). Também foi reportada para acerola em pó uma perda de $26 \%$, em relação ao teor inicial, após 60 dias armazenamento (SOARES et al., 2001).

A partir dos resultados experimentais de acidez total titulável durante o armazenamento, ajustados por equação quadrática (Figura 1c), verifica-se, nas duas embalagens, reduções na acidez total titulável das amostras ao longo do armazenamento. No caso dos materiais em embalagem laminada, as reduções foram menos 
acentuadas, o que pode ser visto na representação dos pontos experimentais onde a acidez das amostras em polietileno apresenta valores inferiores em todos os tempos de armazenamento. Entre os tempos inicial e final, o percentual de acidez das amostras em laminado foi reduzido em 7,9\% e nas amostras em polietileno, em $12,0 \%$, resultando em todas as comparações que as amostras em embalagem laminada conservaram melhor o seu percentual de acidez original. A redução de 7,9\% em embalagem laminada pode ser considerada satisfatória em relação aos resultados obtidos por SOARES (1996) que armazenou acerola em pó em embalagem metalizada de polipropileno bi-orientado revestida com polietileno e verificou redução no percentual de acidez total titulável de cerca de 11,4\% em 60 dias de armazenamento.

Os valores médios do $\mathrm{pH}$ das amostras armazenadas nas duas embalagens são apresentados na tabela 1. Nas embalagens laminadas, o pH se manteve nos níveis iniciais ao longo do armazenamento, apesar da diferença observada aos 50 dias, a qual não denota tendência, por se tratar de um caso isolado. A variação máxima de $\mathrm{pH}$ ao longo do armazenamento nesse tipo de embalagem, verificada entre o tempo zero e os 50 dias, foi de 3,3\%. Em embalagem de polietileno, as amostras mantiveram o $\mathrm{pH}$ inicial ao longo do armazenamento e, da mesma forma que o observado nas amostras em embalagem laminada, a maior diferença em relação à média foi detectada aos 50 dias de armazenamento. Quanto à influência do tipo de embalagem, não se verificam

Tabela 1 - Valores médios de pH do umbu-cajá em pó nas diferentes embalagens durante o armazenamento.

\begin{tabular}{lcc}
\hline & \multicolumn{2}{c}{$\mathrm{pH}$} \\
\cline { 2 - 3 } Período de armazenamento (dia) & Laminada & Polietileno \\
\cline { 2 - 3 } 0 & $3,02 \mathrm{a}^{1}$ & $3,02 \mathrm{a}$ \\
10 & $3,05 \mathrm{a}$ & $3,00 \mathrm{~b}$ \\
20 & $3,08 \mathrm{a}$ & $3,03 \mathrm{~b}$ \\
30 & $3,02 \mathrm{a}$ & $3,01 \mathrm{a}$ \\
40 & $3,07 \mathrm{a}$ & $3,09 \mathrm{a}$ \\
50 & $3,12 \mathrm{a}$ & $3,16 \mathrm{a}$ \\
60 & $3,09 \mathrm{a}$ & $3,05 \mathrm{a}$ \\
$\mathrm{DMS}^{2}$ & \multicolumn{2}{c}{0,04} \\
$\mathrm{MG}^{2}$ & \multicolumn{2}{c}{3,06} \\
$\mathrm{CV}^{2}(\%)^{2}$ & \multicolumn{2}{c}{0,88} \\
\hline
\end{tabular}

${ }^{1}$ Médias não seguidas pela mesma letra nas linhas diferem estatisticamente pelo teste de Tukey a $5 \%$ de probabilidade de erro

${ }^{2}$ DMS: Desvio mínimo significativo; MG: Média geral; CV: Coeficiente de variação. diferenças consistentes durante os 60 dias do armazenamento.

Dos pontos experimentais com ajustes lineares representando o teor de sólidos solúveis totais ( ${ }^{\circ}$ Brix) para as amostras de umbu-cajá em pó (Figura 2a), na embalagem laminada, nota-se que houve uma manutenção aproximada dos níveis iniciais durante os 20 primeiros dias de armazenamento, sem diferenças significativas entre os materiais; entre 20 e 30 dias dá-se uma redução de $35 \%$ e, a partir dos 30 dias até o final do armazenamento, tem-se uma estabilidade estatística no ${ }^{\circ}$ Brix nas amostras em embalagem laminada. Nas embalagens de polietileno, $\mathrm{o}^{\circ}$ Brix das amostras sofreu redução entre os tempos zero e 10 dias, manteve-se estável entre 10 e 30 dias, diminuiu entre 30 e 40 dias e, continuou estável a partir dos 40 dias até o final do armazenamento. Apesar da redução percentualmente expressiva entre 30 e 40 dias (cerca de 44\%), o comportamento estatístico do conjunto de valores revela decréscimo progressivo no ${ }^{\circ}$ Brix, ao longo do armazenamento na embalagem de polietileno, demonstrando superioridade da embalagem laminada

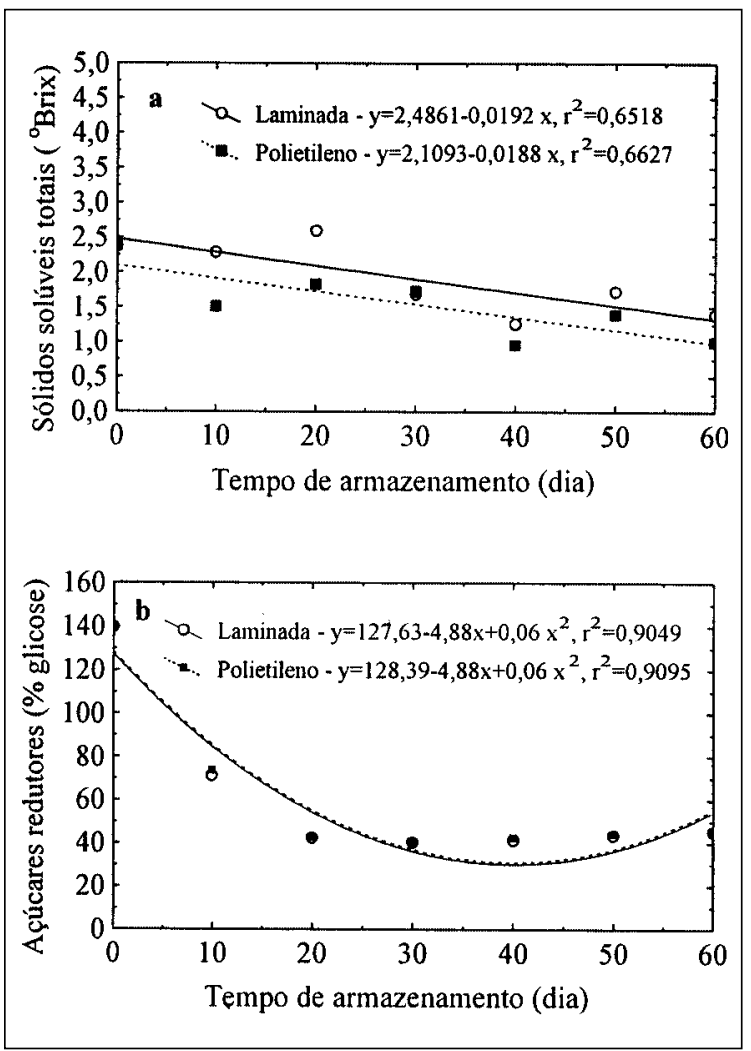

Figura 2 - Valores experimentais dos sólidos solúveis totais ( ${ }^{\circ}$ Brix) (a) e açúcares redutores (b) em função do tempo de armazenamento do umbu-cajá em pó, em diferentes embalagens, com respectivas curvas de ajuste.

Ciência Rural, v. 35, n. 5, set-out, 2005. 
na conservação do ${ }^{\circ}$ Brix dos materiais, ao longo dos 60 dias. LIMA et al. (2002), ao estudarem o armazenamento da polpa congelada de umbu-cajá durante o mesmo tempo, verificaram perda de $2,2 \%$ no teor de sólidos solúveis totais.

Dos valores experimentais de açúcares redutores ajustados por equação quadrática (Figura 2b), observa-se redução nos conteúdos deste constituinte nas polpas de umbu-cajá nos dois tipos de embalagem, entre o início do armazenamento (tempo zero) e os 20 primeiros dias. A partir de 20 dias, os teores permaneceram praticamente estáveis até os 60 dias. Entre embalagens, não se observam diferenças nos teores em nenhum dos tempos. As diferenças entre os teores iniciais e finais nas amostras armazenadas nas duas embalagens foram de aproximadamente $67 \%$. Apesar de ocorrer diminuição no valor de açúcares redutores no decorrer do armazenamento, ainda se obteve um valor final superior ao encontrado por SOARES (1996) ao final de 60 dias de armazenamento de pó de acerola, que reportou um teor de $39,44 \%$ de glicose.

Pelos valores apresentados, na tabela 2, verifica-se a influência do tipo de embalagem sobre o parâmetro luminosidade das amostras de umbu-cajá em pó ao longo do armazenamento. No caso da embalagem laminada, não se constata qualquer tendência de alteração entre as luminosidades das amostras nos tempos. Em se tratando das amostras embaladas em polietileno, verifica-se redução na luminosidade a partir de 40 dias.

Entre embalagens, os valores médios de luminosidade se igualam até os 40 dias; aos 50 e 60 dias, as luminosidades das amostras em embalagem de polietileno se reduzem, demonstrando a influência da exposição à luz, ausente sobre as amostras em embalagem laminada.

Pelos resultados obtidos para o parâmetro intensidade de vermelho $\left(+\mathrm{a}^{*}\right)$ apresentados na tabela 2 constata-se que entre as amostras em embalagem laminada, não ocorreram alterações ao longo do armazenamento, mantendo-se praticamente os mesmos valores médios em todos os tempos avaliados. Contrariamente, AGUIRRE et al. (2003) relataram que a alteração mais evidente na cor da acerola em pó armazenada foi o decréscimo na intensidade de vermelho. Nas amostras em embalagem de polietileno, entre zero e 10 dias, tem-se um aumento neste parâmetro, indicando alteração nos primeiros dias; outros aumentos se sucedem ao longo do tempo, embora em tempos não subseqüentes. Entre embalagens, exceto no tempo zero, o valor do parâmetro $+\mathrm{a}^{*}$ refletiu as alterações detectadas nas amostras embaladas em polietileno a partir do tempo 10, superando os valores medidos nas amostras embaladas em laminado, em todos os casos.

A evolução do parâmetro intensidade de amarelo $\left(+b^{*}\right)$, apresentado na Tabela 2 , não revela diferença entre as amostras, em embalagem laminada, ao longo do armazenamento. Entre embalagens, verificam-se diferenças em todos os tempos a partir de 10 dias, resultado do aumento no valor do parâmetro intensidade de amarelo a partir do tempo 10 nas amostras em polietileno.

As alterações verificadas nas amostras embaladas em polietileno poderiam ser justificadas de acordo com a hipótese levantada por LEE (1983) de

Tabela 2 - Valores médios da luminosidade, intensidade de vermelho (+a*) e intensidade de amarelo (+b* $)$ do umbu-cajá em pó, nas diferentes embalagens durante o armazenamento.

\begin{tabular}{|c|c|c|c|c|c|c|}
\hline \multirow{2}{*}{$\begin{array}{l}\text { Período } \\
\text { armazenamento (dia) }\end{array}$} & \multicolumn{2}{|c|}{ Luminosidade } & \multicolumn{2}{|c|}{ Intensidade de vermelho $\left(+\mathrm{a}^{*}\right)$} & \multicolumn{2}{|c|}{ Intensidade de amarelo $\left(+b^{*}\right)$} \\
\hline & Lamin. & Poliet. & Lamin. & Poliet. & Lamin. & Poliet. \\
\hline 0 & $46,27 \mathrm{a}^{1}$ & $46,27 \mathrm{a}$ & $13,33 \mathrm{a}$ & $13,33 \mathrm{a}$ & $28,00 \mathrm{a}$ & $28,00 \mathrm{a}$ \\
\hline 10 & $46,43 \mathrm{a}$ & $46,67 \mathrm{a}$ & $13,93 \mathrm{~b}$ & $14,57 \mathrm{a}$ & $29,40 \mathrm{~b}$ & $30,40 \mathrm{a}$ \\
\hline 20 & $47,30 \mathrm{a}$ & $46,23 \mathrm{a}$ & $13,23 \mathrm{~b}$ & $14,53 \mathrm{a}$ & $28,77 \mathrm{~b}$ & $30,40 \mathrm{a}$ \\
\hline 30 & $45,67 \mathrm{a}$ & $47,13 \mathrm{a}$ & $13,37 \mathrm{~b}$ & $14,63 \mathrm{a}$ & $28,57 \mathrm{~b}$ & $30,10 \mathrm{a}$ \\
\hline 40 & $45,57 \mathrm{a}$ & $45,77 \mathrm{a}$ & $13,47 \mathrm{~b}$ & $14,77 \mathrm{a}$ & $28,37 \mathrm{~b}$ & $30,27 \mathrm{a}$ \\
\hline 50 & $46,80 \mathrm{a}$ & $44,47 \mathrm{~b}$ & $13,87 \mathrm{~b}$ & $15,07 \mathrm{a}$ & $28,97 \mathrm{~b}$ & $30,90 \mathrm{a}$ \\
\hline 60 & $46,57 \mathrm{a}$ & $44,27 \mathrm{~b}$ & $13,43 \mathrm{~b}$ & $15,07 \mathrm{a}$ & $28,33 \mathrm{~b}$ & $30,57 \mathrm{a}$ \\
\hline $\mathrm{DMS}^{2}$ & \multicolumn{2}{|c|}{1,58} & \multicolumn{2}{|c|}{0,50} & \multicolumn{2}{|c|}{0,96} \\
\hline $\mathrm{MG}^{2}$ & \multicolumn{2}{|c|}{46,10} & \multicolumn{2}{|c|}{14,04} & \multicolumn{2}{|c|}{29,3} \\
\hline $\mathrm{CV}(\%)^{2}$ & \multicolumn{2}{|c|}{2,05} & \multicolumn{2}{|c|}{2,15} & \multicolumn{2}{|c|}{1,98} \\
\hline
\end{tabular}

${ }^{1}$ Médias não seguidas pela mesma letra nas linhas diferem estatisticamente pelo teste de Tukey a $5 \%$ de probabilidade de erro. ${ }^{2}$ DMS: Desvio mínimo significativo; MG: Média geral; CV: Coeficiente de variação; 
que o decréscimo dos parâmetros da cor (L, a e b) implica o escurecimento da amostra, que pode ser devido à degradação de pigmentos e/ou do ácido ascórbico.

\section{CONCLUSÕES}

As amostras sofreram alterações durante o armazenamento com a embalagem laminada preservando melhor, ao final do tempo de armazenamento, a acidez total titulável e os parâmetros associados à cor. O tipo de embalagem não influenciou os teores de açúcares redutores, de ácido ascórbico e $\mathrm{pH}$.

\section{REFERÊNCIAS}

AGUIRRE, J.M. et al. Desidratação de acerola. In: FITO, P.; et al. Deshidratación de alimentos y propiedades relacionadas. Valencia: UPV, 2003. p.133-138.

ALVES, R.M.V. Embalagem para frutas e hortaliças desidratadas e frutas secas. Campinas : CETEA/ITAL, 2001. $12 \mathrm{p}$.

BOBBIO, F.O.; BOBBIO, P.A. Introdução à química de alimentos. 2.ed. São Paulo: Varela, 1992. 223p.

AOAC - Official of analysis of the Association of Official Analytical Chemists. 14.ed. Washington: Williams Horwitz, 1997. 1141p.

BENASSI, M.T.; ANTUNES, A.J. A comparison of metaphosphoric and oxalic acids as extractant solutions for the determination of vitamin $\mathrm{C}$ in selected vegetables. Arquivos de Biologia e Tecnologia, Curitiba, v.31, n.4, p.507-513, 1998.

FIGUEIRÊDO, R.M.F. et al. Armazenamento do suco de acerola microencapsulado. Revista Brasileira de Produtos Agroindustriais, Campina Grande, v.3, n.1, p.1-6, 2001.

GARCIA, E.E.C. et al. Embalagens plásticas: propriedades de barreira. Campinas: ITAL, 1989. 44p.

GOMES, P.M.A. Estudo da polpa de acerola (Malpighia emarginata D.C) desidratada em leite de jorro. 2002. $86 f$. Dissertação (Mestrado em Engenharia Agrícola) - Centro de Ciências e Tecnologia, Universidade Federal de Campina Grande.
Instituto ADOLFO LUTZ. Normas Analíticas do Instituto Adolfo Lutz: métodos químicos e físicos para análise de alimentos. 3.ed. São Paulo, 1985. V.1, 533p.

LEE, F.A. Basic food chemistry. Westport: The Avi, 1983. $564 \mathrm{p}$.

LIMA, E.D.P.A. et al. Umbu-cajá (Spondias spp): aspectos de pós-colheita e processamento. João Pessoa: UFPB/ Idéia, 2002. 57p.

PIERGIOVANNI, L. Materiais de embalagem e tecnologias de envase. In: BARUFFALDI, R.; OLIVEIRA, M.N. Fundamentos de tecnologia de alimentos. São Paulo: Atheneu, 1998. p.219-278.

RITZINGER, R. et al. Caracterização e avaliação de germoplasma de umbu-cajazeira no Estado da Bahia. In: CONGRESSO BRASILEIRO DE MELHORAMENTO DE PlantAS, 1., 2001, Goiânia. Anais... Goiânia: Sociedade Brasileira de Melhoramento de Plantas, 2001. CD ROM.

SANKAT, C.K.; CASTAIGNE, F. Foaming and drying behaviour of ripe bananas. Lebensm.-Wiss. u.-Techonol, v.37, n.5, p.517-525, 2004

SILVA, F.A.S.; AZEVEDO, C.A.V. Versão do programa computacional Assistat para o sistema operacional Windows. Revista Brasileira de Produtos Agroindustriais, Campina Grande, v.4, n.1, p.71-78, 2002

SOARES, E.C. Desidratação da polpa de acerola (Malpihia emarginata D.C) pelo processo "foam mat". 1996. 153f. Dissertação (Mestrado em Tecnologia de Alimentos) - Centro de Ciências Agrárias, Universidade Federal do Ceará.

SOARES, E.C. et al. Desidratação da polpa de acerola (Malpighia emarginata D.C.). Ciência e Tecnologia de Alimentos, Campinas, v.21, n.2, p.164-170, 2001.

TRAVAGLINI, D.A. et al. Desidratação de frutas. Campinas : CETEA/ITAL, 2001. 40p.

UBOLDI, M. Desidratação por camada de espuma ("foam mat"). 1971. 32f. Dissertação (Mestrado em Ciência de Alimentos) - Universidade Estadual de Campinas.

VERNON-CARTER, E.J. et al. Effect of foaming agents on the stability, rheological properties, drying kinetics and flavour retention of tamarind foam-mats. Food Research International, v.34, n.7, p.587-598, 2001. 